\title{
MODELOWANIE DYNAMICZNYCH PROCESÓW PRZESTRZENNYCH
}

\begin{abstract}
$\mathrm{Z}$ a ry s t r e ś c i. Artykuł przedstawia ekonometryczną analizę procesu przestrzennoczasowego na przykładzie PKB w wybranych krajach europejskich. Przedmiotem rozważań są przestrzenne i przestrzenno-czasowe trendy oraz autozależności charakteryzujące składnikową strukturę badanego procesu. Składniki te są podstawą do specyfikacji dynamicznych modeli przestrzennych. Zaproponowane w artykule specyfikacje dynamicznych modeli przestrzennych poddaje się empirycznej weryfikacji.
\end{abstract}

S ł o w a k 1 u c z o w e: trend przestrzenno-czasowy, autokorelacja, model przesunięć przestrzennych, dynamiczny model przestrzenny.

\section{WPROWADZENIE}

Przedmiotem rozważań niniejszego opracowania jest ekonometryczne modelowanie dynamicznych procesów przestrzennych. Jest to kolejny artykuł z cyklu analiz ekonomicznych procesów przestrzennych i przestrzennoczasowych, który przedstawia metodologię ekonometrycznego modelowania struktury tych procesów (patrz także Szulc, 2008, 2009).

Ilustracją empiryczną przeprowadzonych rozważań jest, podobnie jak w poprzednich artykułach, kształtowanie się PKB per capita w wybranych krajach europejskich. Sa to: Austria, Niemcy, Czechy, Polska, Słowacja oraz Wegry. Dane dotyczą regionów ustalonych według europejskiej klasyfikacji systemu NUTS i pochodzą z bazy EUROSTATU.

W pracy Szulc (2008) analizowano PKB per capita na wyodrębnionym obszarze w 2004 r. Badano strukturę składnikową pojedynczego procesu przestrzennego $Z\left(\mathbf{s}_{i}\right)$, obserwowanego na płaszczyźnie w przestrzennych lokalizacjach $\mathbf{s}_{i}=\left[x_{i}, y_{i}\right]$, gdzie $i=1,2, \ldots, 84$. W pracy Szulc (2009) do przeprowa- 
dzonej wcześniej analizy dołączono aspekt czasowy, tj. rozważano zmiany PKB per capita na wyodrębnionym obszarze w latach 2000-2006. Badano składnikową strukture procesu przestrzennego $w$ kolejnych latach, tj. $Z_{t}\left(\mathbf{s}_{i}\right), \mathbf{s}_{i}=\left[x_{i}, y_{i}\right], i=1,2, \ldots, 84, t=1,2, \ldots, 7$, przyjmując $\mathrm{w}$ ten sposób warunkowe względem czasu podejście do analizy procesu przestrzennoczasowego. Wnioski dotyczące łącznej struktury przestrzenno-czasowej, prowadzące do odpowiedniego modelu empirycznego, wyciagnięto wówczas jedynie w odniesieniu do tzw. trendu przestrzenno-czasowego. Ponadto zaproponowano pewną ograniczoną specyfikację dynamicznego modelu przestrzennego.

Niniejszy artykuł łączy wspomniane podejścia prezentując bardziej rozwinięte modele, opisujące składnikową strukturę procesu przestrzenno-czasowego $Z\left(\mathbf{s}_{i}, t\right)$, gdzie $\mathbf{s}_{i}=\left[x_{i}, y_{i}\right], i=1,2, \ldots, 84, t=1,2, \ldots, 7$.

Nadal obowiązują następujące założenia (por. Szulc, 2009):

1. Ekonomiczne procesy przestrzenne wykazują trendy przestrzenne i/lub przestrzenno-czasowe, które utożsamia się ze zmieniającą się w przestrzeni i/lub w czasie wartością średnią procesu.

2. Zazwyczaj wykazują one także autozależności, które w strukturze procesu tworzą składnik autoregresyjny.

3. Składnik autoregresyjny tworzy jednorodny/stacjonarny proces przestrzenny lub/i przestrzenno-czasowy.

Oznacza to, że przyjmuje się podstawową strukturę składnikową procesu przestrzenno-czasowego, którą symbolicznie można zapisać w następującej postaci ogólnej:

$$
Z\left(\mathbf{s}_{i}, t\right)=P\left(\mathbf{s}_{i}, t\right)+A(\mathbf{W}, u) Z\left(\mathbf{s}_{i}, t\right)+\varepsilon\left(\mathbf{s}_{i}, t\right),
$$

gdzie:

$P\left(\mathbf{s}_{i}, t\right)$ - trend przestrzenno-czasowy, zazwyczaj wyrażany w postaci trójwymiarowej funkcji wielomianowej;

$A(\mathbf{W}, u)$ - sumacyjny przestrzenno-czasowy operator przesunięć, zdefiniowany w taki sposób, że W (macierz powiązań przestrzennych) powoduje przesunięcia zmiennej $\mathrm{w}$ przestrzeni, natomiast $u$ (operator przesunięć wstecz) powoduje przesunięcia w czasie;

$\varepsilon\left(\mathbf{s}_{i}, t\right)$ - przestrzenno-czasowy proces białego szumu.

\section{WNIOSKI Z POPRZEDNICH BADAŃ}

W zakresie badania trendów przestrzennych stwierdzono, iż trendy takie występują we wszystkich latach badanego okresu. We wszystkich przypadkach dopasowano modele stopnia 1 . Wykres 1 . przedstawia teoretyczne powierzchnie trendu. Niemal równoległe położenie tych powierzchni pokazuje, że trendy 
przestrzenne PKB per capita na badanym obszarze w zasadzie nie zmieniają się co do kształtu w kolejnych latach. Powierzchnie odpowiadające kolejnym okresom są położone coraz wyżej względem osi wartości PKB, co oznacza, że wartość średnia PKB per capita w regionach rośnie w czasie.

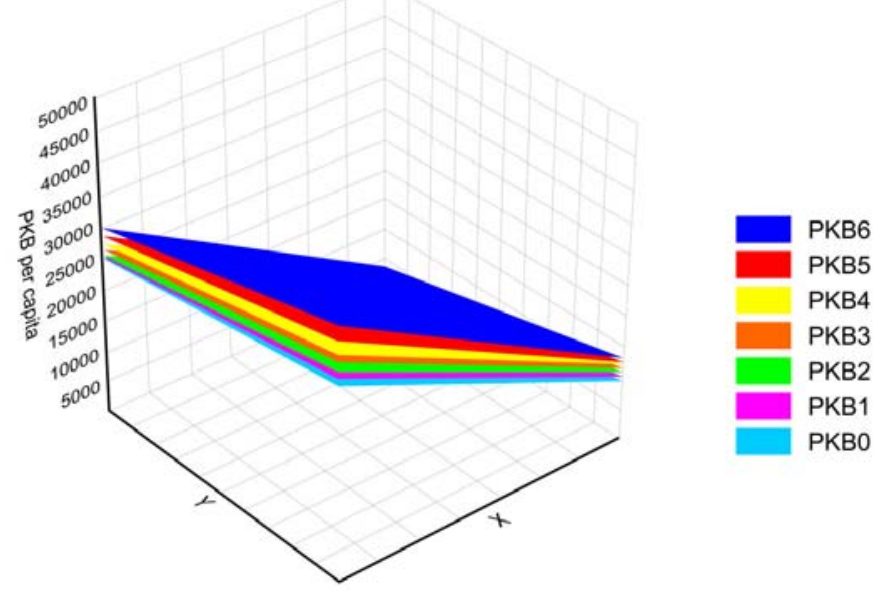

Wykres 1. Powierzchnie wartości wyrównanych PKB per capita według trendu przestrzennego w latach 2000-2006

Źródło: opracowanie własne.

\section{Wniosek 1.}

PKB per capita $\mathrm{w}$ rozważanym układzie przestrzennym w badanym okresie kształtuje się według przestrzenno-czasowego trendu stopnia 1.

Empiryczny model przestrzenno-czasowego trendu PKB per capita przedstawia równanie (2)

$$
P \hat{K} B_{i, t}=\underset{(509,882)}{14367,2-\underset{(0,000707)}{0,017656} x_{i}}-\underset{(0,001012)}{0,009296} y_{i}+\underset{(113,242)}{748,582 t} t
$$

$R^{2}=0,55038$.

W zakresie badania autokorelacji przestrzennej rzędu pierwszego ${ }^{1}$ dla reszt $\mathrm{z}$ dopasowanych wcześniej modeli trendu, stwierdzono niezbyt wysoką ale statystycznie istotną autokorelację dodatnią we wszystkich latach.

\section{Wniosek 2.}

Wartości PKB per capita $\mathrm{w}$ regionach sąsiedzkich są do siebie podobne.

W kolejnych latach wartości statystyki Morana zmniejszały się ${ }^{2}$.

\footnotetext{
${ }^{1}$ Obliczono wartości statystyk Morana oraz oceniono ich istotność. Wyniki zaprezentowano w pracy Szulc (2009)

${ }^{2}$ Patrz przypis 1.
} 


\section{Wniosek 3.}

Podobieństwo PKB per capita w regionach sąsiedzkich maleje w czasie.

Badając zakres przestrzenny autokorelacji ${ }^{3}$ stwierdzono (w zależności od zastosowanej metody) istotność współczynników pierwszego oraz piątego rzę$\mathrm{du}$, lub też rzędu pierwszego, trzeciego, czwartego, a nawet piątego. Wartości odpowiednich współczynników można przedstawić na wykresie. Na przykład, wykres 2. prezentuje przestrzenne korelogramy szóstego rzędu dla PKB per capita w 2006 r. (korelogramy dla pozostałych lat przedstawiono na zbiorczym wykresie 3.).

(a)

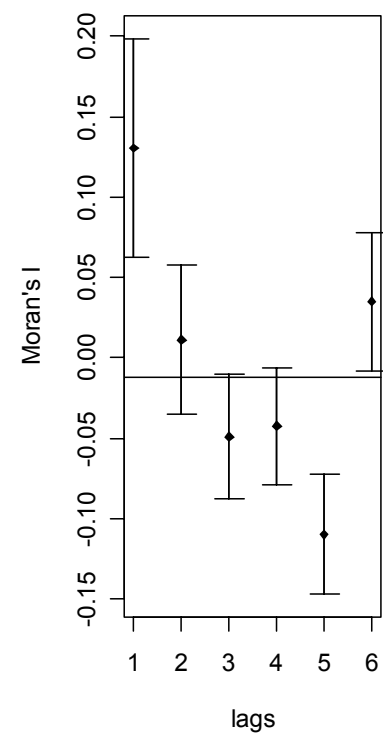

(b)

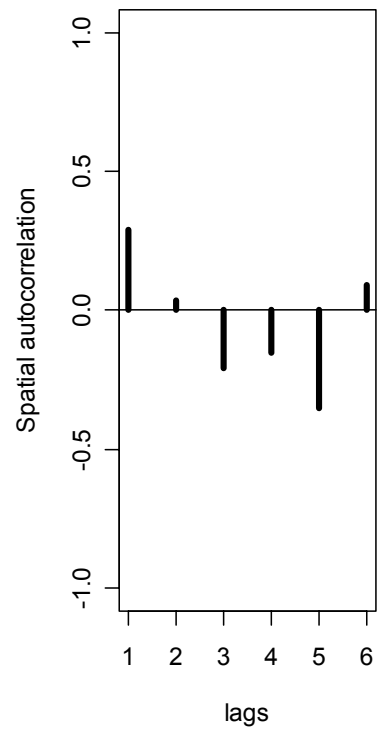

Wykres 2. Przestrzenne korelogramy szóstego rzędu dla PKB w 2006 r.: (a) współczynniki Morana, (b) klasyczne współczynniki korelacji.

Źródło: opracowanie własne.

\section{Wniosek 4.}

Autokorelacja przestrzenna PKB per capita na badanym obszarze może dotyczyć nie tylko tzw. najbliższych sąsiadów.

\footnotetext{
${ }^{3}$ Do badania wykorzystano dwie metody. Pierwsza polegała na obliczeniu i ocenie istotności odpowiednich statystyk Morana, przy założeniu sąsiedztwa różnych rzędów, druga zaś polegała na wykorzystaniu klasycznego współczynnika korelacji, obliczanego dla każdego ustalonego przesunięcia przestrzennego. Wartości i oceny istotności odpowiednich współczynników przedstawiono w pracy Szulc (2009).
} 


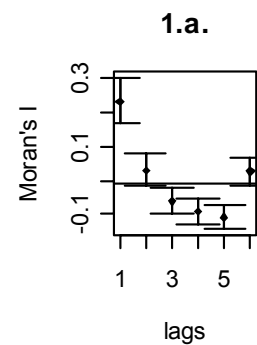

3.a.

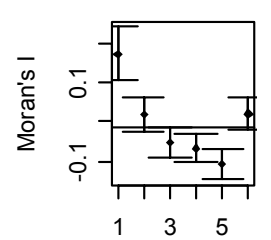

lags

5.a.

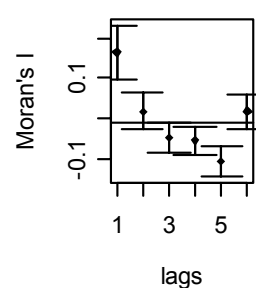

1.b.

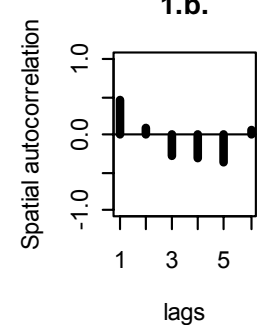

3.b.

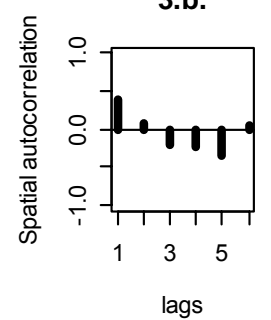

5.b.

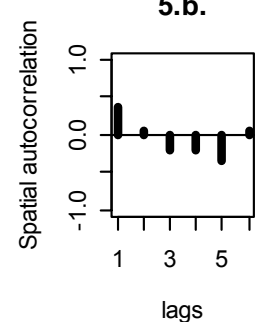

2.a

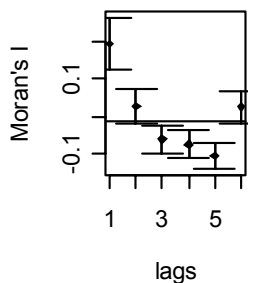

4.a.

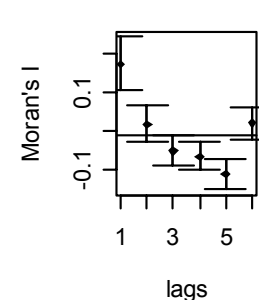

6.a.

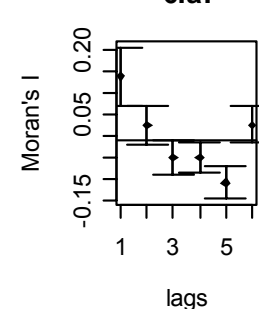

2.b.

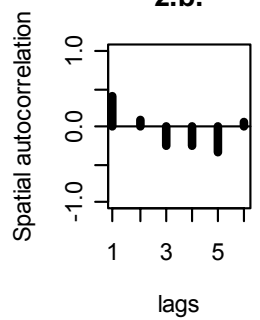

4.b.

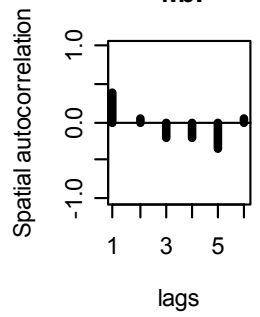

6.b.

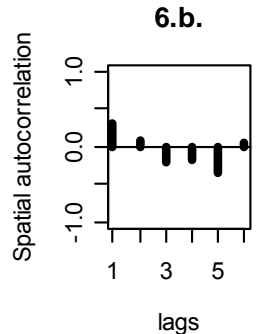

Wykres 2. Przestrzenne korelogramy szóstego rzędu dla PKB w latach 2000-2005.

*Kolejne pary wykresów dotyczą kolejnego jednego roku.

Źródło: opracowanie własne.

Ze względu na niejednoznaczność wyników co do autokorelacji przestrzennej wyższych rzędów, uzyskanych za pomocą różnych metod, za najbardziej prawdopodobną uznano autokorelację pierwszego rzędu.

\section{Wniosek 5.}

Proponuje się następująca postać przestrzennego modelu ekonometrycznego PKB per capita:

$$
P K B_{i}=\theta_{00}+\theta_{10} x_{i}+\theta_{01} y_{i}+\rho \mathbf{W}\left(P K B_{i}\right)+\varepsilon_{i},
$$

taką samą dla każdego roku badanego okresu. 


\section{MODELOWANIE TRENDOWO-AUTOREGRESYJNEJ STRUKTURY PRZESTRZENNO-CZASOWEGO PROCESU PKB}

Przeprowadzone badania prowadzą do rozważenia następujących modeli przestrzenno-czasowych.

Model z trendem przestrzenno-czasowym i przestrzenną autoregresja

Przeprowadzenie oddzielnych analiz przestrzennych dla każdego punktu w czasie oraz porównanie uzyskanych wyników, skłoniło do sformułowania wniosku ogólnego, odnoszącego się do łącznej przestrzenno-czasowej struktury badanego procesu, w postaci następującego modelu teoretycznego:

$$
P K B_{i, t}=\theta_{000}+\theta_{100} x_{i}+\theta_{010} y_{i}+\theta_{001} t+\rho \mathbf{W}\left(P K B_{i, t}\right)+\varepsilon_{i, t},
$$

Wyniki szacowania parametrów i weryfikacji modelu (4) przedstawia tabela 1.

Tabela 1. Zestawienie wyników estymacji i weryfikacji modelu (4)

\begin{tabular}{|c|c|c|c|c|}
\hline Parametry & $\begin{array}{c}\text { Szacunki } \\
\text { parametrów }\end{array}$ & Błędy standardowe & Statystyki $z$ & $\operatorname{Pr}(>|z|)$ \\
\hline$\theta_{000}$ & 8584,5 & 875,05 & 9,8104 & 0,0000000 \\
$\theta_{100}$ & $-0,010805$ & 0,001068 & $-10,1139$ & 0,0000000 \\
$\theta_{010}$ & $-0,005248$ & 0,001021 & $-5,1403$ & 0,0000003 \\
$\theta_{001}$ & 447,98 & 112,72 & 3,9742 & 0,0000710 \\
\hline$\rho=0,41449$ & \\
test LR: $49,408, p$-value: 0,000000 & \\
\hline Statystyka Walda: $70,115, p$-value: 0,000000 & \\
AlC: 11754 (AlC dla Im: 11801$)$ & \\
\hline Autokorelacja reszt \\
Test LM: $0,0032316, p$-value: 0,95467
\end{tabular}

Źródło: obliczenia własne.

Model z trendem przestrzenno-czasowym i przesunięciami przestrzennymi charakteryzuje się istotnymi parametrami, reszty nie wykazują autokorelacji $i$ jest on lepszy od modelu uwzględniającego jedynie trend.

Model z trendem przestrzenno-czasowym oraz przestrzenna, a także czasową autoregresja

Istnienie bardzo silnej autokorelacji czasowej PKB per capita (współczynnik autokorelacji czasowej rzędu pierwszego dla reszt modelu $\mathrm{z}$ trendem przestrzenno-czasowym stopnia 1 . równa się 0,9951$)$ uzasadnia włączenie do modelu opisującego strukturę PKB składnika $P K B_{i, t-1}$. Zatem kolejna specyfikacja modelu jest następująca:

$$
P K B_{i, t}=\theta_{000}+\theta_{100} x_{i}+\theta_{010} y_{i}+\theta_{001} t+\alpha P K B_{i, t-1}+\rho \mathbf{W}\left(P K B_{i, t}\right)+\varepsilon_{i, t} .
$$

Wyniki szacowania parametrów oraz weryfikacji modelu (5) przedstawia tabela 2. 
Tabela 2. Zestawienie wyników estymacji i weryfikacji modelu (5)

\begin{tabular}{|c|c|c|c|c|}
\hline Parametry & $\begin{array}{c}\text { Szacunki } \\
\text { parametrów }\end{array}$ & Błędy standardowe & Statystyki $z$ & $\operatorname{Pr}(>|z|)$ \\
\hline$\theta_{000}$ & 161,68 & 121,88 & 1,3265 & 0,18467 \\
$\theta_{100}$ & $-0,00021899$ & 0,00014506 & $-1,5097$ & 0,13111 \\
$\theta_{010}$ & $-0,00030464$ & 0,00012093 & $-2,5191$ & 0,01176 \\
$\theta_{001}$ & 125,35 & 13,627 & 9,1985 & 0,00000 \\
$\alpha$ & 1,0420 & 0,0042246 & 246,6556 & 0,00000 \\
\hline$\rho=-0,034921$ & & \\
test LR: $17,139, p$-value: 0,000000 & \\
\hline Statystyka Walda: $17,519, p$-value: 0,000000 & \\
AlC: 7643,4 \\
\hline Autokorelacja reszt \\
Test LM: $49,851, p$-value: 0,000000
\end{tabular}

Źródło: obliczenia własne.

Pomimo poprawy ogólnego stopnia dopasowania modelu, nie można uznać go za ostateczny, ponieważ w resztach pojawiła się autokorelacja.

Model z trendem przestrzenno-czasowym, przestrzenna, czasową oraz przestrzenno-czasową autoregresją

Podobnie jak współczynniki autokorelacji przestrzennej oraz czasowej, współczynnik autokorelacji przestrzenno-czasowej pierwszego rzędu okazał się istotny. Jego wartość wyniosła 0,1636. Dlatego następny model przestrzennoczasowej struktury PKB uwzględnia dodatkowo składnik $\mathbf{W}\left(P K B_{i, t-1}\right)$. Przyjmuje on następującą postać:

$$
\begin{aligned}
P K B_{i, t} & =\theta_{000}+\theta_{100} x_{i}+\theta_{010} y_{i}+\theta_{001} t+\alpha P K B_{i, t-1} \\
& +\rho \mathbf{W}\left(P K B_{i, t}\right)+\gamma \mathbf{W}\left(P K B_{i, t-1}\right)+\varepsilon_{i, t} .
\end{aligned}
$$

Wyniki szacowania parametrów i weryfikacji modelu (6) przedstawia tabela 3.

Tabela 3. Zestawienie wyników estymacji i weryfikacji modelu (6)

\begin{tabular}{|c|c|c|c|c|}
\hline Parametry & $\begin{array}{c}\text { Szacunki } \\
\text { parametrów }\end{array}$ & Błędy standardowe & Statystyki $z$ & $\operatorname{Pr}(>|z|)$ \\
\hline$\theta_{000}$ & 252,99 & 115,64 & 2,1879 & 0,02868 \\
$\theta_{100}$ & $-0,00028963$ & 0,00013734 & $-2,1088$ & 0,03496 \\
$\theta_{010}$ & $-0,00027527$ & 0,00014 & $-2,4146$ & 0,01575 \\
$\theta_{001}$ & 78,610 & 13,9317 & 5,6485 & 0,00000 \\
$\alpha$ & 1,0458 & 0,0040193 & 260,1819 & 0,00000 \\
$\gamma$ & $-0,42254$ & 0,057249 & $-7,3808$ & 0,00000 \\
\hline
\end{tabular}

Źródło: obliczenia własne. 
Rozważany model charakteryzuje się istotnymi parametrami. Reszty modelu nie wykazują autokorelacji. Pod względem ogólnego dopasowania do danych jest on najlepszym spośród proponowanych w tej pracy modeli.

\title{
4. PODSUMOWANIE
}

Rozważania niniejszego artykułu potwierdzają znaczenie badania własności i struktury przestrzennych i przestrzenno-czasowych procesów ekonomicznych dla ich modelowania.

Ekonometryczne modele procesów przestrzenno-czasowych powinny mieć charakter dynamiczny, co wyraża się w odpowiednim wyspecyfikowaniu trendowo-autoregresyjnej struktury, charakteryzującej czasowe, przestrzenne i przestrzenno-czasowe tendencje, oraz opóźnienia i przesunięcia przestrzenne lub/i przestrzenno-czasowe obserwowanych zależności.

PKB per capita na wyodrębnionym obszarze w badanym okresie realizuje przestrzenno-czasowy proces, wykazujący trend przestrzenno-czasowy oraz autozależności przestrzenne i przestrzenno-czasowe. Specyfikacja dynamicznego modelu przestrzennego dla PKB per capita doprowadziła do otrzymania „dobrego" modelu empirycznego.

\section{LITERATURA}

Szulc E. (2008), Analiza struktury ekonomicznych procesów przestrzennych na przykładzie PKB $w$ wybranych krajach europejskich, „Acta Universitatis Nicolai Copernici”, Ekonomia XXXVIII, z. 388, 7-20.

Szulc E. (2009), Analiza zmian w czasie struktury ekonomicznych procesów przestrzennych na przykładzie PKB w wybranych krajach europejskich, referat wygłoszony na III Konferencji Naukowej im. Profesora Aleksandra Zeliasia, pt. Modelowanie i prognozowanie zjawisk społeczno-gospodarczych, Zakopane 5 - 8 maja 2009, złożony do druku w: J. Pociecha (red.), „Współczesne problemy modelowania i prognozowania zjawisk społecznogospodarczych”, Studia i Prace Uniwersytetu Ekonomicznego w Krakowie.

\section{MODELLING OF DYNAMIC SPATIAL PROCESSES}

\begin{abstract}
A b s t r a c t. The paper concerns econometric modelling of the dynamic spatial processes on the example of GDP per capita in chosen European countries. The considerations of the paper are focused on investigations of the structure of components of the spatio-temporal process. As a result of the analysis some specifications of the dynamic spatial models are obtained. Next the issues of the estimation and verification of the models are presented. The main conclusion from the analysis is that the econometric models of the spatio-temporal processes ought to be of the dynamic character, e.g. considering spatial and spatio-temporal trends and spatial, temporal and spatiotemporal autodependences as well.
\end{abstract}

K e y w o r d s: spatio-temporal trend, autocorrelation, spatial lag model, dynamic spatial model. 